\title{
THE FIRST CHEMICAL IDENTIFICATION OF POLYOLEFIN (PO) WASTE BLENDS USING INFRARED SPECTROSCOPY
}

\author{
SULTAN MAJED AL-SALEM \\ Environment \& Life Sciences Research Centre (ELSRC), Kuwait Institute for Scientific Research (KISR), Kuwait
}

\begin{abstract}
Locally, the State of Kuwait is in need of good practices and national strategies that can take advantage of the accumulated solid waste, ridding the environment of various issues and stressors. In this work, compounded rolls of the various samples originating from plastic solid waste were used for the preparation of the test specimens. Samples were compounded to have the following percentages of virgin linear low density polyethylene and plastic film waste (wt./wt.\%): 100/0, 75/25, 50/50, 25/75 and $0 / 100$. The samples were compounded using blown film extrusion with a die head temperature of $175^{\circ} \mathrm{C}$. Films of the different formulations were exposed to accelerated weathering in accordance with test method ASTM D 4329. Samples were mounted on the racks facing the ultra violet lamps with no empty spaces in the panels. This is in order to maintain a uniform repeatable test condition in accordance with cycle A procedure. The chemical printing of the evolved chemicals was achieved using Fourier Transform Infrared Spectroscopy and the spectra were recorded with a resolution of $4 \mathrm{~cm}^{-1}$ using Diamond Universal ATR attachment. Four interferogram scans were averaged to give the spectra from 500 to $5000 \mathrm{~cm}^{-1}$ using the Attenuated Total Reflection technique. A noted reduction in the carbonyl index determined from the FTIR spectra of the $75 / 25$ samples supports the claim of the relative stability of the blend. This can lead to the development of a product from waste plastic material that reduced the burden of accumulation in developing and developed societies alike. In addition, the thermal properties determined along with the degradation kinetics parameters estimation revealed after the execution of this research project, have shown the stability of the blend for further development as a standalone product.
\end{abstract}

Keywords: plastic waste, polymer, solid waste, spectroscopy, carbonyl index, polyolefin.

\section{INTRODUCTION}

Thermoplastic polyolefin (PO) polymers such as polyethylene (PE) and polypropylene (PP), exhibit good mechanical and physical properties making them ideal for versatile use and applications [1]-[3]. These include packaging, consumer product commodities, leisure articles and building materials. The increasing demand on PO polymers has had its consequences as of late, namely in increasing petrochemical ventures around the globe and the increase in plastic solid waste (PSW) generation and accumulation. This is especially true when it comes to the State of Kuwait, where crude oil refining and petrochemical ventures are supported by the government of the state as it is considered the main contributor to the national gross domestic product (GDP) [4]. In addition, feedstock to plastic production industries is noted to be cheap due to the abundance in petroleum refinery cuts.

Various schemes make use of PSW, the form of mechanical recycling as a swift means for reducing the solid waste (SW) accumulation in communities. Mechanical recycling of plastics depends solely on the integrity of the produced article's integrity [5]. A mechanical recycling processing line is deemed successful when the used blend of virgin and PSW materials result in a product that substitute market accepted ones [6]. To this end, it is deemed essential to be able to investigate the properties of such blends using various chemical and thermal characterisation techniques. 
Fourier transform infrared spectroscopy (FTIR) is a technique used in material characterization by examining the existing bonds in a sample. It works by searing different beams of varying frequencies and measuring the absorption of the beam by the sample. Each bond in a sample has a different energy and angle, thus absorbs the beam at specific wavelengths. The raw data collected from the different beams is modelled using Fourier Transform to present the measurement as absorption per wavelength. This allows the measurements of a wider range of wavelengths with high resolution. Moreover, weathering and ageing tests are typically conducted to estimate the durability of samples and study the change in the polymers matrix. Turku and Kärki [7] studied fire-retarded (aluminium trihydrate, zinc borate, melamine, graphite, titanium dioxide) wood-polypropylene composites (WPC) under accelerated conditions. $\alpha$-keto carbonyl groups of cellulose increased together with vinyl groups due to PP oxidation due to weathering. Moreover, the melamine peak was decreased on the front and backside of WPC due to leaching by water to the samples studied. Sharma et al. [8] characterised dumbbell specimens of Sago starch filled LLDPE composites and used infrared to study them. It was noted that ether and carbonyl peaks increased, suggesting the degradation of elastomer free radical reactions. Rajakumar et al. [9] used FTIR to determine the extent of degradation post natural weathering of PP samples. The carbonyl index increased slowly up to 40 days of summer exposure. Lactone, ester, ketone, and carboxylic acid indices showed a similar trend in summer and winter seasons.

Henceforth, this work was initiated to characterise various blends of PSW (originating from plastic film waste) with virgin commercial grade plastic (i.e. LLDPE) typically used in plastic film conversion. The work conducted in this study is a part of a continuing effort that stems out experimental results with the aim of having a comprehensive and novel picture of plastic film products rich in waste content [10]-[15]. The materials chosen are commercially available and used for various application, hence are of interest to study post use as PSW and converted plastics. This specific study focuses on the alterations caused by accelerated weathering (ageing) on the film samples originating from reclaimed PSW in Kuwait. The work carried out is useful for developing more resistant materials available on the market, as well as, extend the durability of the developed blends. Chemical alterations are reported here, in addition to the blends thermal stability post accelerated weathering. This paper will detail the efforts carried out and show the work conducted in detail with analysis of data gathered following on previous communications [16], [17]. To the best of author's knowledge, no such attempt was conducted in the past in investigating PSW blends.

\section{MATERIALS AND METHODS}

\subsection{Samples compounding and preparation}

Rolls of the various samples used in this work, were used for the preparation of the test specimens. Samples were compounded to have the following percentages of virgin linear low density polyethylene (LLDPE) and plastic film waste (virgin/waste, wt./wt.\%): 100/0, 75/25, $50 / 50,25 / 75$ and $0 / 100$. Throughout this manuscript the virgin LLDPE will be denoted as V and the PSW will be denoted as W. The samples were compounded using blown film extrusion with a die head temperature (DHT) of $175^{\circ} \mathrm{C}$. Readers are referred to Al-Salem et al. [15]-[17] for further details on compounding and the PSW constituting elements as they are out of the scope in this communication. The thin rolls $(100 \mu \mathrm{m})$ were cut into standard test specimens size of $20 \times 1 \mathrm{~cm}$. 


\subsection{Accelerated weathering}

Accelerated (artificial) indoor weathering (ageing) tests are commonly used for studying materials integrity. Films of the different formulations were exposed to AW in accordance with ASTM D 4329 [18]. The conducted weathering test was accomplished in the WMRU Laboratory in ELSRC. Samples were mounted on the racks facing the UV lamps with no empty spaces in the panels. This is in order to maintain a uniform repeatable test conditions. Cycle A procedure was used for general applications durability testing, i.e. $8 \mathrm{~h}$ of UV exposure at $60^{\circ} \mathrm{C}$ followed by $4 \mathrm{~h}$ of condensation at $50^{\circ} \mathrm{C}$. At the end of each continuous weathering test, the chamber was cooled to room temperature and trays were set to rest on a flat surface for a minimum of $24 \mathrm{~h}$. Samples were laid to rest for a minimum of 72 hours before characterization following the methodology of Johnson et al. [19], Al-Salem [20] and Al-Salem et al. [16]. A minimum of four replicates were exposed to the different exposure duration in the QUV machine chamber. Ultra Violet (UV) lamps irradiance was also selected according to ASTM D 4329 [18], and the lamp type was set to be $0.68 \mathrm{~W} \mathrm{~m}^{-2}$ (irradiance) for normal lamp operation, which will maintain almost $5000 \mathrm{~h}$ of operation for the lamps. The irradiance sensor was calibrated every $400 \mathrm{~h}$ of lamp operation during the UV cycle under normal test temperature. The equipment used was cleaned every $800 \mathrm{hrs}$ to remove scale deposits resulting from water evaporation during the condensation cycles.

\subsection{FTIR analysis}

Attenuated Total Reflection (ATR) works by producing the infrared (IR) beam into a solid crystal with a high refractive index. The sample is typically placed on the crystal and firmly pressed on it. The IR beam will reflect at the surface of the crystal creating evanescent waves in the sample. The IR beam reaches a detector at the other side of the crystal and the measurement is determined based on the absorption of the evanescent beam allowing the desired measurement to be conducted. The equipment used in this work was a Perkin Elmer UK (Spectrum Two Model) FTIR-spectrometer. Spectra were recorded with a resolution of $4 \mathrm{~cm}^{-1}$ using Diamond Universal ATR attachment; four interferogram scans were averaged to give the spectra from 500 to $5000 \mathrm{~cm}^{-1}$ using the Attenuated Total Reflection (ATR) technique. At least two replicas of samples were used to recorded each spectra. Figures below show the equipment used.

\subsection{Thermal characterisation}

Thermal degradation of virgin/waste blend samples was investigated using a Shimadzu TGA50 thermobalance equipped with a data acquisition/analysis software (TA Instrument) set to record the data every second under five heating rates $(\beta)$ (i.e. 5, 10, 15, 20 and $25^{\circ} \mathrm{C} \mathrm{min}^{-1}$ ). A constant flow of pure $(99.99 \%)$ dry nitrogen with a flow rate of $50 \mathrm{ml} \mathrm{min}^{-1}$ was maintained throughout the experiments. The measurements were conducted using $5 \pm 0.1 \mathrm{mg}$ samples from room temperature to $550^{\circ} \mathrm{C}$ made with triplicates showing high repeatability with standard deviation not exceeding $1 \%$ in accordance with the International Confederation for Thermal Analysis and Calorimetry (ICTAC) recommendations previously published in Vyazovkin et al. [21], [22] for non-isothermal (dynamic) thermogravimetry; to diminish sample size influences on the kinetics [21]-[23]. Furthermore, samples of $1 \pm 0.01 \mathrm{mg}$ were subjected to thermogravimetry in the same instrument under a constant flow of pure oxygen gas $\left(99.99 \%\right.$ ) with a flow rate of $50 \mathrm{ml} \mathrm{min}^{-1}\left(\beta\right.$ equal to $\left.15^{\circ} \mathrm{C} \mathrm{min}{ }^{-1}\right)$. A Perkin Elmer (Model Jade, US) equipped with PYRIS analysis software was used to test control and exposed 
samples using a $5 \pm 0.1 \mathrm{mg}$ samples taken from the middle section of the specimens. Aluminium oxide $\left(\mathrm{Al}_{2} \mathrm{O}_{3}\right)$ crucibles made were used for both samples and reference materials. Crystallinity measurements were determined using scans of the second heating cycle between 50 to $230^{\circ} \mathrm{C}$ based on the peak area of the heat flow curve between $60^{\circ} \mathrm{C}$ and $130^{\circ} \mathrm{C}$, with a nitrogen $\left(\mathrm{N}_{2}\right)$ gas flowrate of $20 \mathrm{ml} \mathrm{min}^{-1}$ and a heating rate of $10^{\circ} \mathrm{C} \mathrm{min}^{-1}$. Cooling rate was set at $15^{\circ} \mathrm{C} \mathrm{min}^{-1}$ in similar conditions [24], [25]. The second heating cycle was used in the crystallinity analysis following the initial heating run, as it will eliminate inherited effects of thermal histories and weathering on the specimens [25]. Oxidation induction temperature (OIT) was conducted using similar weight for the studied samples. Samples were heated using a rate of $10^{\circ} \mathrm{C} \mathrm{min}{ }^{-1}$ with a $\mathrm{N}_{2}$ flowrate of $20 \mathrm{ml} \mathrm{min}{ }^{-1}$. Samples were then held for 5 minutes at $70^{\circ} \mathrm{C}$ to settle followed by the introduction of oxygen $\left(\mathrm{O}_{2}\right)$ gas flowrate of $20 \mathrm{ml} \mathrm{min}-1$. Samples were then heated from 70 to $230^{\circ} \mathrm{C}$ at a rate of $2^{\circ} \mathrm{C}$ $\min ^{-1}[26]$.

\section{RESULTS AND DISCUSSION}

Accelerated weathered PO polymer blends originating from PSW blends, were analyzed in order to characterize and identify the chemical degradation products. The weathering extents were conducted in accordance with the experimental procedure described earlier and to the extent of the threshold limit of each formulation and described earlier in [16]. The carbonyl group, which is formed by the oxidation of polyethylene [26]-[28], was quantified using carbonyl index (CI) estimations based on the data obtained from the FTIR analysis (eqn (1)). Other chemical products noted to be prominent in polymer degradation were also analysed (e.g. lactone, ester/aldehydes, and carboxylic acid indices). This was done to monitor the extent of degradation by dividing the corresponding peak to the reference polyethylene (PE) band (eqns (2)-(4)).

$$
\begin{gathered}
\text { Carbonyl Index }(\mathrm{CI})=\frac{\text { Absorbance at } 1714 \mathrm{~cm}^{-1}}{\text { Absorbance at } 1470 \mathrm{~cm}^{-1}(\mathrm{PE} \text { Band })}, \\
\text { Lactone Index }=\frac{\text { Absorbance at } 1770 \mathrm{~cm}^{-1}}{\text { Absorbance at } 1470 \mathrm{~cm}^{-1}(\mathrm{PE} \mathrm{Band})}, \\
\text { Ester/Aldhyde Index }=\frac{\text { Absorbance at } 1733 \mathrm{~cm}^{-1}}{\text { Absorbance at } 1470 \mathrm{~cm}^{-1}(\mathrm{PE} \mathrm{Band})}, \\
\text { Carboxylic Acid Index }=\frac{\text { Absorbance at } 1698 \mathrm{~cm}^{-1}}{\text { Absorbance at } 1470 \mathrm{~cm}^{-1}(\mathrm{PE} \text { Band })} .
\end{gathered}
$$

A sample of the compiled spectra of virgin/waste PE formulations, which were treated under accelerated weathered conditions are presented in Figs 1-3. Table 1 also shows the prominent and most noted band in PO polymer degradation and IR detection [29]-[31]. The band observed in the range between 700 to $760 \mathrm{~cm}^{-1}$ corresponds to the rocking vibration associated to the crystallinity of the polymer [32]. The band between $1460-1480 \mathrm{~cm}^{-1}$ relates to $\mathrm{CH}_{2}$ bending vibration, while the band between $2850-2950 \mathrm{~cm}^{-1}$ associated with the asymmetric and symmetric $\mathrm{CH}$ stretching [32]. The band between 1000 and $1300 \mathrm{~cm}^{-1}$ corresponds to the formulation of hydroperoxide $\mathrm{ROOH}$ [33]. In general, peroxide radical $\mathrm{ROO}^{*}$ is formed after macro free radical $\mathrm{R}^{*}$, reacting with the ambient oxygen. The peroxide radical $\mathrm{ROO}^{*}$ can then separate hydrogen from the polymer, forming polymer centred free radical $\mathrm{P}^{*}$ and a hydroperoxide $\mathrm{ROOH}$ [28], [33]. As a result, the hydroperoxide $\mathrm{ROOH}$ degrades rapidly and forms highly reactive radicals that accelerate the oxidation process forming ketone, esters, and acids [33]. The major bands in Figs 1-3 were the spectra between 1700 and $1800 \mathrm{~cm}^{-1}$, which relates to the accumulation of carbonyl group and its products. 


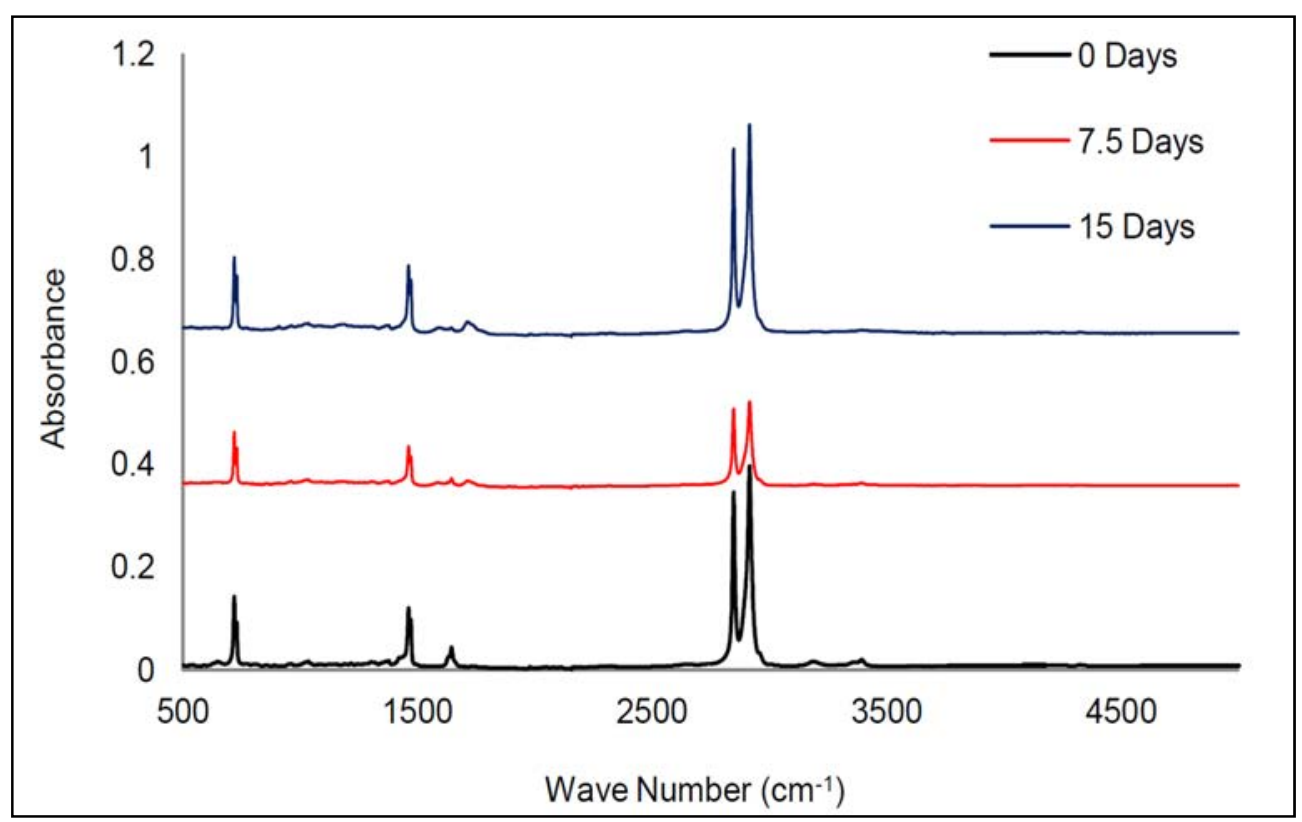

Figure 1: FTIR-ATR spectra for the 100 wt.\% virgin linear low density PE samples exposed to accelerated weathering.

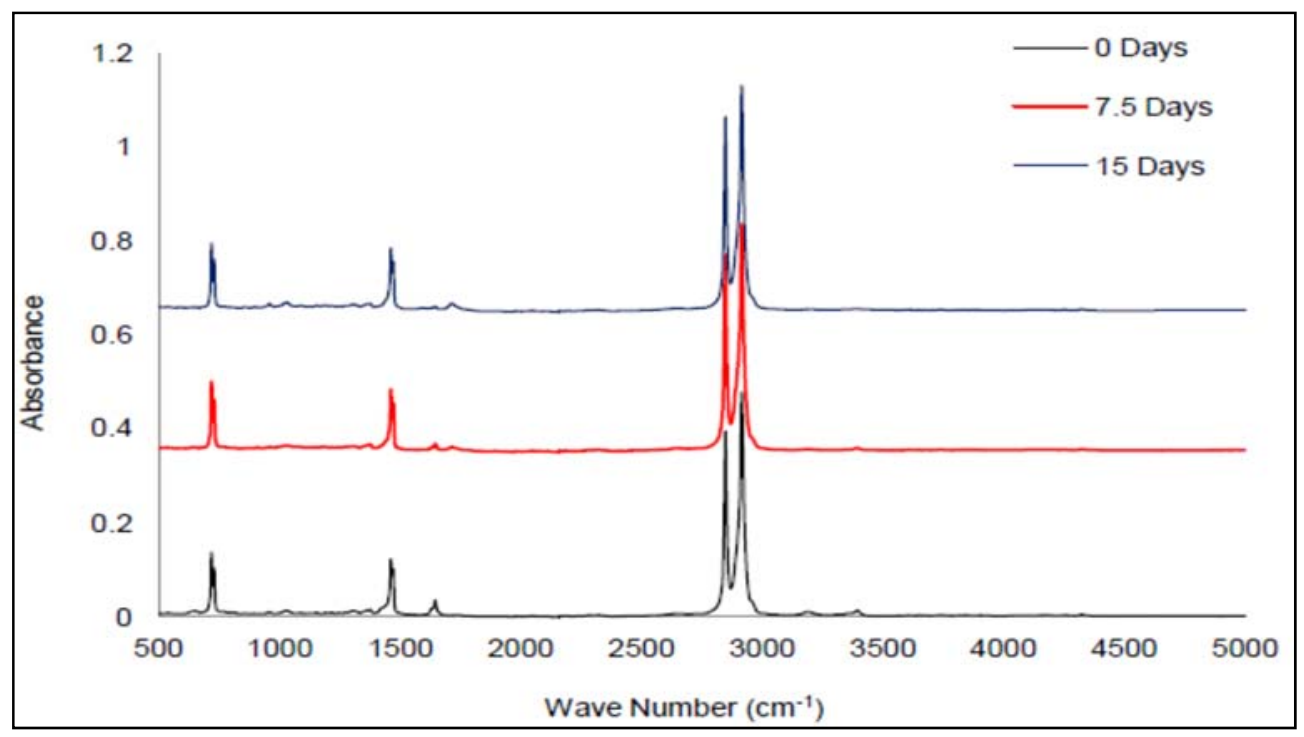

Figure 2: FTIR-ATR spectra for the $100 \mathrm{wt} . \%$ virgin linear low density PE and 25 wt.\% PSW samples exposed to accelerated weathering. 


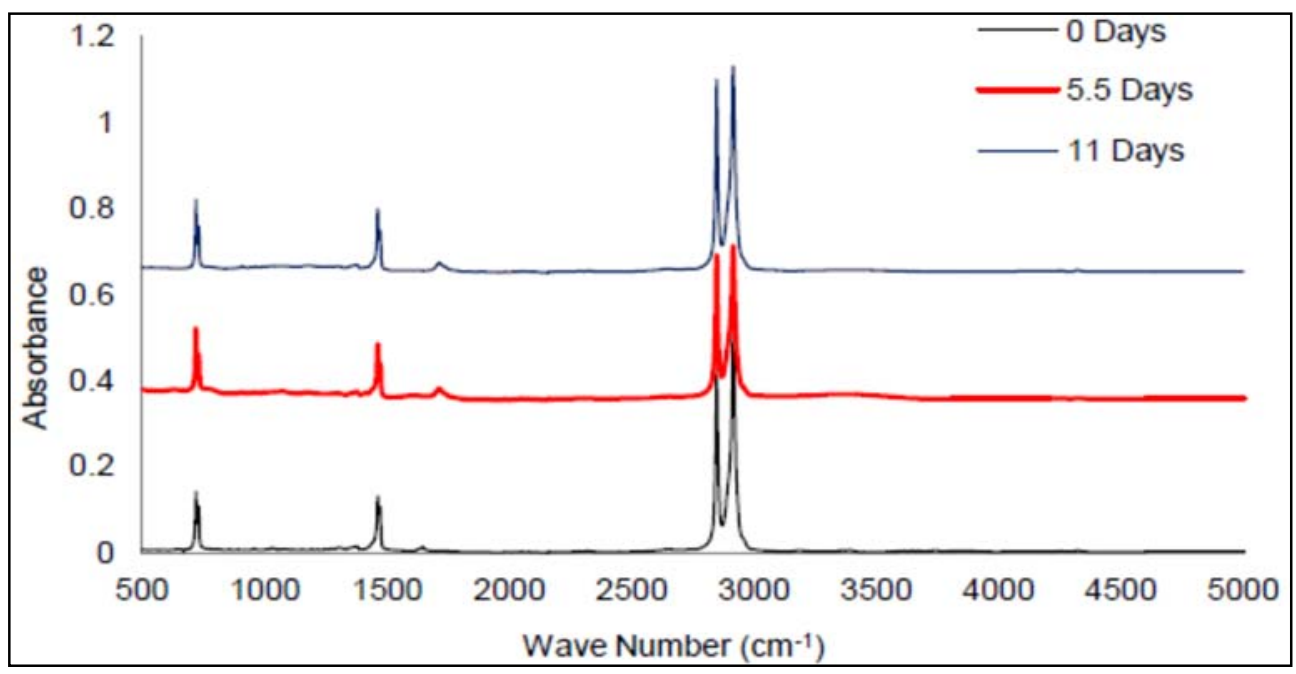

Figure 3: FTIR-ATR spectra for the $100 \mathrm{wt} . \%$ PSW samples exposed to accelerated weathering.

Table 1: Assignment of absorption bands of IR spectrum.

\begin{tabular}{c|l|l}
\hline Wave number $\left(\mathrm{cm}^{-1}\right)$ & Assigned Group/Product & Reference \\
\hline 1770 & C=O Stretching (Lactone) & \\
1733 & C-O Stretching (Ester/Aldhyde) & Gulmine et al. [29] \\
1714 & C=O Stretching (Ketone) & \\
\hline 1470 & PE Band & D'Amelia et al. [30] \\
\hline 1698 & C=O Stretching (Carboxylic Acid) & Gulmine et al. [29] \\
\hline 730 & $\mathrm{CH}_{2}$ rocking vibration, crystalline & \multirow{2}{*}{ Matuana et al. [31] } \\
\hline 718 & $\mathrm{CH}_{2}$ rocking vibration, amorphous & \\
\hline
\end{tabular}

The dominant absorption band at around $1714 \mathrm{~cm}^{-1}$ corresponds to the $\mathrm{C}=\mathrm{O}$ stretching vibration of terminal ketone [29], and it is more prominent with the increase in waste content by weight in the PE formulations (Figs 2, 3).

The ketone absorbance after 5.5 days of continuous exposure increased by approximately $46.7 \%$ between the $100 \mathrm{wt} . \%$ virgin polymer and the $100 \mathrm{wt} . \%$ PSW samples. In addition, with extended aging for each formulation, it was noted that the intensity of the absorption band increases. Additional bands for other carbonyl products start to appear such as ester/aldehyde band at $1733 \mathrm{~cm}^{-1}$, lactone band at $1770 \mathrm{~cm}^{-1}$, and carboxylic acid band at $1689 \mathrm{~cm}^{-1}$ (see Fig. 4).

The CI is an indication for the oxidation degree for each sample, notably increasing with weathering duration and waste content of the samples. Therefore, the stability of the samples against oxidation is in the following order: $75 \mathrm{~V} / 25 \mathrm{~W}>50 \mathrm{~V} / 50 \mathrm{~W}>100 \mathrm{~V} / 0 \mathrm{~W}>25 \mathrm{~V} / 75 \mathrm{~W}>$ $0 \mathrm{~V} / 100 \mathrm{~W}$. However, it is very important to mention that for $50 \% \mathrm{PE}$ virgin content and above, the CI stabilized at the last stages of aging compared to samples with more waste content $(>50 \%)$. A good explanation for this oxidation rate stability could be due to the 


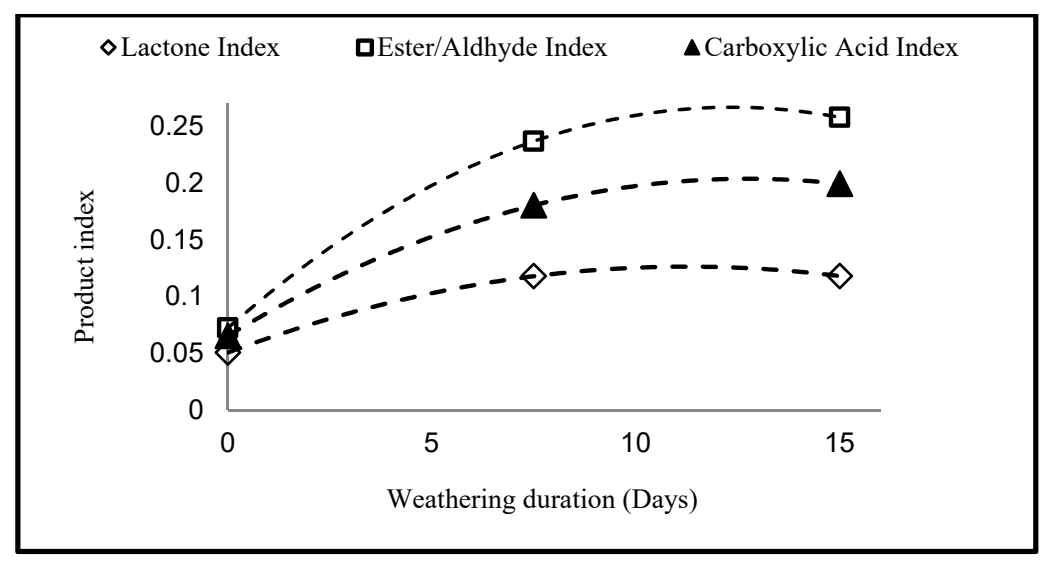

Figure 4: Variation of lactone index, ester/aldhyde index and carboxylic index for the 100 PE sample.

effects of the oxidation and cross-linking processes [29]. Samples with 50\% virgin content and above favoured cross-linking over oxidation; therefore, carbonyl formation decreased and stabilized at last stages of aging [29]. For samples with 50\% waste content and below, product indices homogenously increase as weathering duration increases. Ester/aldehyde is the major oxidizing product (highest index) followed by carboxylic acid and lactone. Furthermore, the values of indices for all products increase as the virgin content in the samples increases from $50 \%$ to $100 \%$.

Ester/aldehyde groups are being produced clearly, increasing from $0.12(50 \mathrm{~V} / 50 \mathrm{~W})$ to $0.24(100 \mathrm{~V} / 0 \mathrm{~W})$ for PE films with $50 \%$ waste content and below. The group also increases with aging time. This is an indication for the oxidation of virgin PE to accumulate carbonyl products at high values. Slight increase is noticed for Ester/aldehyde groups for PE films with $50 \%$ waste content and above (see figures above). The carboxylic acid and lactone indices increase with aging because of the oxidation of all samples [33]. Nevertheless, carboxylic acid index is always higher than lactone index for all PE samples. This is attributed to the fact that it is the final stable product of the oxidation process, which causes the accumulation of carboxylic acid [9]. Unlike the 50\% waste content and below samples, heterogeneous trends are observed for $75 \%$ and $100 \%$ waste content in the samples. This can be clearly seen by the increase in products indices during the early stages of aging, while inconsistent pattern is noticed in the later stages. The values of indices for these samples also are lower than the values for 50\% virgin content and above. This reflects the chemical degradation and oxidation that waste PE have already gone through during its lifetime; therefore, carbonyl products indices for these samples are lower and heterogeneous.

The degree of crystallinity is presented in Table 2 following the thermal characterisation conducted. The virgin LLDPE exhibited a similar degree of crystallinity as to the other materials tested in this work (34\%). The structure of the materials tested in this work being semi-crystalline allows for the degradation within the polymers matrix due to weathering [34], [35]. Loss of chain ends due to oxygen permeability is denoted to be the main reason of the detected calorimetric behaviour [26]. The alteration in the mechanical integrity of the LLDPE samples studied in this work, namely in Young's modulus, strain and stress at rupture, indicate the loss of amorphous region at 7.5 days of exposure [16]. This points 
Table 2: $\quad$ Degree of crystallinity (\%) measurements and oxidation induction temperature $\left({ }^{\circ} \mathrm{C}\right)$ from DSC thermal analysis.

\begin{tabular}{c|c|c|c}
\hline $\begin{array}{c}\text { Material } \\
(\mathrm{v} / \mathrm{w} \text { wt.\%) }\end{array}$ & $\begin{array}{c}\text { Exposure } \\
\text { duration (days) }\end{array}$ & $\begin{array}{c}\text { Degree of crystallinity } \\
(\%) \text { 2nd heating cycle }\end{array}$ & $\begin{array}{c}\text { Oxidation induction } \\
\text { temp. }\left({ }^{\circ} \mathrm{C}\right)\end{array}$ \\
\hline \multirow{3}{*}{$100 / 0$} & 0 & 34 & 200.5 \\
& 7.5 & 40 & 196.6 \\
& 15 & 35 & 181 \\
\hline \multirow{2}{*}{$75 / 25$} & 0 & 35 & 196.6 \\
& 7.5 & 35 & 195.2 \\
& 15 & 41 & 180 \\
\hline \multirow{3}{*}{$50 / 50$} & 0 & 34 & 189.3 \\
& 5.5 & 32 & 185.6 \\
\hline \multirow{3}{*}{$25 / 75$} & 11 & 34 & 183.8 \\
& 0 & 34 & 187.8 \\
& 5.5 & 34 & 185 \\
\hline \multirow{2}{*}{$0 / 100$} & 11 & 35 & 183.2 \\
& 5.5 & 34 & 175.7 \\
\hline
\end{tabular}

towards the excessive cross-linking and branching reactions that the polymer undergoes due to photo-degradation which are evident with the increase in crystallinity. The decrease in crystallinity at threshold was expected due to the increase in the evolution of chemicals from the termination reaction for the studied chemical mechanism associated with PE degradation [36].

The materials studied in this work were also subjected to thermogravimetric analysis and a sample of the results is shown in Fig. 5. The onset, mideste and maximum degradation temperatures showed very similar values in this investigation. This indicates that the waste content has no effect on the thermal characteristics of the material. It should also be noted that the content of $2 \mathrm{wt} . \%$ of polypropylene (PP) in the waste materials seems to be irrelevant on the thermogravimetric behaviour of the materials. This can be attributed to the fact that PP was in minimal weight content that did not warrant a dedicated step in the thermogram. The char content increased with the increasing waste content, which is related to the stabiliser content in the plastic products of west and number heating cycles the materials were subjected to. The thermal analysis has revealed valuable insight into the behaviour of PSW blends under different conditions that can be used as a guideline for future product development. The history of the PSW, being exposed to natural weathering at reclamation sight and processed with various heating loops, has influenced the specimens behaviour in this study. Thermo-mechanical degradation was an influential factor on the behaviour of the materials since the blends varied than the LLDPE samples in their characteristics [10], [15], [17].

\section{CONCLUSION}

Blends constituting plastic solid waste (PSW) from polyolefin (PO) polymers origin were investigated in this work with the aim of determining the effect of the solid waste ratio on the materials properties. The focus was on the chemical properties and products evolved due to degradation which were investigated using infrared spectroscopy. Accelerated weathering was conducted in this work to determine the degradation profile of the samples. The waste 


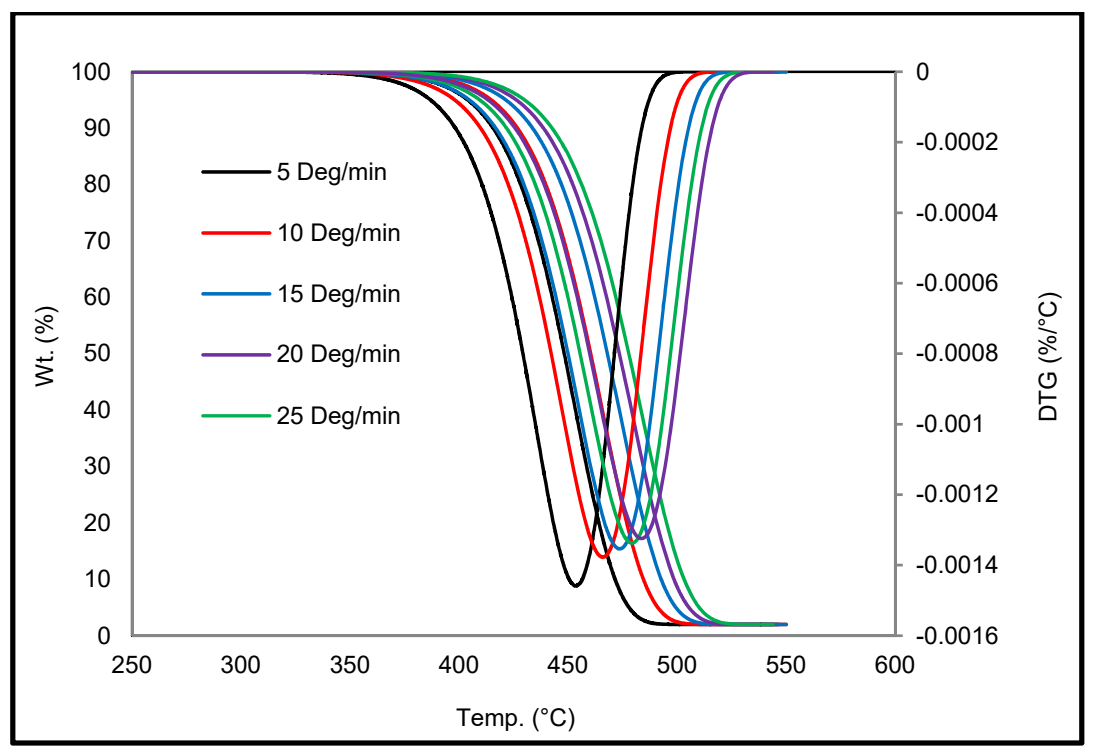

Figure 5: Thermogram of the virgin/waste (75/25) unexposed sample subjected to nitrogen weight loss analysis showing weight loss (\%) (primary scale) and first derivative (secondary scale).

materials were incorporated using 25 to $100 \%$ by weight and the specimens were tested under two different weathering durations to showcase the degradation profile of the specimens. Thermal stability determine using thermogravimetry showed a somewhat comparable results in the measurements. This was attributed to the fact that the samples were all made of PO polymers and degrade in similar temperature ranges regardless of their past processing history. The crystallinity degree was noted to be similar before exposure to weathering tests. Minor changes with respect to the degree of crystallinity were noticed as weathering progresses which is a consequence of the change in crystal size. The 75/25 samples showed a change in crystallinity toward midpoint of weathering time resulting in a $41 \%$ degree of crystallinity from the $35 \%$ originally estimated. This was related to the immiscibility of the polymers and crystal size change due to oxidation. This is supported with the detected energy absorption curves noted in the DSC analysis. The structure of the LLDPE was also noted to be influential in the changes notable in the oxidation induction temperature (OIT) analysis carried out in this study. From the Thermogravimetry and DSC studies conducted, the $75 / 25$ was noted to be most stable and can be used as a good material for product development applied for indoor and outdoor purposes. The morphological analysis has led to the detection of mosaic cracks in all directions that progressed as weathering took place. However, the reduction in the carbonyl index determined from the FTIR spectra of the 75/25 supports the claim of the relative stability of the blend. The work conducted in this study can benefit from density measurements and EDS analysis to support some of the experimental findings. This can lead to the development of a product from waste plastic material that reduced the burden of accumulation in developing and developed societies alike. The thermal degradation kinetics of the blend material should be assessed in the future to determine the materials recycling potential and viability via thermal and chemical means. 


\section{ACKNOWLEDGEMENTS}

The author would like to thank the Kuwait Institute for Scientific Research (KISR), Swansea University and EQUATE Petrochemical Company for funding and supporting this research project. The continuous support and encouragement of the management of the Environment and Life Sciences Research Centre (ELSRC) at KISR is graciously acknowledged. Eng. A. Al-Qattan (EQUATE R\&D Department Manager) and Mr. O. Al-Qabandi (EQUATE R\&D Technology Specialist) are gratefully acknowledged for their help and support. The team members and staff within the rota of Project EM074C that contributed to this work are also appreciated with sincere gratitude.

\section{REFERENCES}

[1] Inuwa, I.M. et al., Influence of exfoliated graphite nanoplatelets on the flammability and thermal properties of polyethylene terephthalate/polypropylene nanocomposites. Polymer Degradation \& Stability, 110, pp. 137-148, 2014. DOI: 10.1016/ j.polymdegradstab.2014.08.025.

[2] Mourad, A.I., Thermo-mechanical characteristics of thermally aged polyethylene/polypropylene blends. Materials \& Design, 31(2), pp. 918-929, 2010. DOI: 10.1016/j.matdes.2009.07.031.

[3] Muthukumar, T., Aravinthan, A. \& Mukesh, D., Effect of environment on the degradation of starch and pro-oxidant blended polyolefins. Polymer Degradation and Stability, 95(10), pp. 1988-1993, 2010.

DOI: 10.1016/j.polymdegradstab.2010.07.017.

[4] Al-Dhafeeri, A.T., Al-Salem, S.M., Al-Wadi, M.H., Sultan, H.H. \& Karam, H.J., Variation in gas chromatography (GC) analysis in setting up laboratory protocols for waste to energy novel fixed bed reactor setups. International Journal of Energy Production \& Management, 2(3), pp. 294-305, 2017. DOI: 10.2495/eq-v2-n3-294305.

[5] Kartalis, C.N., Papaspyrides, C.D., Pfaendner, R., Hoffmann, K. \& Herbst, H., Mechanical recycling of post-used HDPE crates using the restabilization technique. I: Influence of reprocessing. Journal of Applied Polymer Science, 73(9), pp. 1775-1785, 1999. DOI: 10.1002/(sici)1097-4628(19990829)73:9<1775::aid-app20>3.0.co;2-g.

[6] Al-Salem, S.M., Lettieri, P. \& Baeyens, J., Recycling and recovery routes of plastic solid waste (PSW): A review. Waste Management, 29(10), pp. 2625-2643, 2009. DOI: 10.1016/j.wasman.2009.06.004.

[7] Turku, I. \& Kärki, T., Accelerated weathering of fire-retarded wood-polypropylene composites. Composites Part A: Applied Science and Manufacturing, 81, pp. 305-312, 2016. DOI: 10.1016/j.compositesa.2015.11.028.

[8] Sharma, N., Chang, L.P., Chu, Y.L., Ismail, H., Ishiaku, U.S. \& Mohd Ishak, Z.A., A study on the effect of pro-oxidant on the thermo-oxidative degradation behaviour of sago starch filled polyethylene. Polymer Degradation \& Stability, 71(3), pp. 381-393, 2001. DOI: $10.1016 / \mathrm{s} 0141-3910(00) 00189-0$.

[9] Rajakumar, K., Sarasvathy, V., Chelvan, A.T., Chitra, R. \& Vijayakumar, C.T., Natural weathering studies of polypropylene. Journal of the Polymers and the Environment, 17(3), pp. 191-202, 2009. DOI: 10.1007/s10924-009-0138-7.

[10] Al-Salem, S. et al., Thermal and morphological study of post accelerated weathering virgin/waste polyolefin blends. Final Report, Project Code: EM074C, Mar. 2018.

[11] Al-Salem, S., Al-Dousari, N., D’Souza, M. \& Al-Zekri, W., Mechanical and physical evaluation of high content waste/virgin polyolefin blends exposed to natural and 
accelerated weathering. Annual Progress Report, Project Code: PC017C, KISR No. 13633, Oct. 2016.

[12] Al-Salem, S., Mechanical and physical evaluation of high content waste/virgin polyolefin blends exposed to natural and accelerated weathering. Progress Report No. 1, Project Code: PC017C, KISR No. 13230, Feb. 2015.

[13] Al-Salem, S., Mechanical and physical evaluation of high content waste/virgin polyolefin blends exposed to natural and accelerated weathering. Volume III: Accelerated (laboratory controlled) weathering study. Final report, Project PC017C, Nov. 2017.

[14] Al-Salem, S.M. et al., Effect of die head temperature (DHT) at compounding stage on the degradation of linear low density polyethylene (LLDPE)/plastic film waste blends post accelerated weathering. International Journal of Polymer Science, Article ID $5147209,2016$.

[15] Al-Salem, S.M., Al-Hazza'a, A.A., Al-Rowaih, A.A. \& Asiri, F.M., Using scanning electron microscopy (SEM) as a tool for knowhow development in identifying plastic film products originating from solid waste. Proceedings of the Microscience Microscopy Congress 2017, Manchester, UK, 3-7 July, pp. 370041, 2017.

[16] Al-Salem, S.M., Abraham, G., Al-Qabandi, O.A. \& Dashti, A.M. Investigating the effect of accelerated weathering on the mechanical and physical properties of high content plastic solid waste (PSW) blends with virgin linear low density polyethylene (LLDPE). Polymer Testing, 46, pp. 116-121, 2015.

DOI: 10.1016/j.polymertesting.2015.07.008.

[17] Al-Salem, S.M., Al-Hazza, A.A., Behbehani, M.H., Al-Rowiah, A.A. \& Al-Rowaih, S.F., Characterisation of waste polyolefin blends using thermal and imaging techniques aimed for product development. Proceedings of the Wessex Institute of Technology (WIT) Transactions Materials Characterisation 2017 8th International Conference on Computational Methods and Experiments in Material and Contact Characterisation, vol. 116, Tallinn, Estonia, 21-23 Jun., pp. 37-48, 2017.

[18] ASTM D 4329, Standard practice for fluorescent UV exposure of plastics. American Society for Testing and Materials, Philadelphia, Penn, 2005.

[19] Johnson, D.A., Urich, J.L., Rowell, R.M., Jacobson, R. \& Courtfield, D.F., Weathering characteristics of fiber-polymer composites. Proceedings of Fifth International Conference Woodfiber-plastic Composites, 1998.

[20] Al-Salem, S.M., Influence of natural and accelerated weathering on various formulations of linear low density polyethylene (LLDPE) films. Materials \& Design, 30(5), pp. 1729-1736, 2009. DOI: 10.1016/j.matdes.2008.07.049.

[21] Vyazovkin, S., Burnhamb, A.K., Criadoc, J.M., Pérez-Maquedac, L.A., Popescud, C. \& Sbirrazzuolie, N., ICTAC Kinetics Committee recommendations for performing kinetic computations on thermal analysis data. Thermochimia Acta, 520(1-2), pp. 119, 2011. DOI: 10.1016/j.tca.2011.03.034.

[22] Vyazovkin, S. et al., 2014. ICTAC Kinetics Committee recommendations for collecting experimental thermal analysis data for kinetic computations. Thermochimia Acta, 590, pp. 1-23, 2014. DOI: 10.1016/j.tca.2014.05.036.

[23] Al-Salem, S.M. et al., Thermal degradation kinetics of virgin polypropylene (PP) and PP with starch blends exposed to natural weathering. Industrial \& Engineering Chemistry Research, 56(18), pp. 5210-5220, 2017. DOI: 10.1021/acs.iecr.7b00754.

[24] ISO 11357-1, British Standards (BS) Implementation of the International Standards Organization, Plastics-Differential scanning calorimetry (DSC) Part 1: General principles, 2009. 
[25] ISO 11357-3, British Standards (BS) Implementation of the International Standards Organization, Plastics-Differential scanning calorimetry (DSC) Part 3: Determination of temperature and enthalpy of melting and crystallization, 2011.

[26] Ojeda, T. et al., Degradability of linear polyolefins under natural weathering. Polymer Degradation and Stability, 96(4), pp. 703-707, 2011.

DOI: $10.1016 /$ j.polymdegradstab.2010.12.004.

[27] ISO 11357-6, Plastics-Differential scanning calorimetry (DSC) Part 6: Determination of oxidation induction time (isothermal OIT) and oxidation induction temperature (dynamic OIT), 2008.

[28] Briassoulis, D., Aristopoulou, A., Bonora, \& Verlodt, I., Degradation characterisation of agricultural low-density polyethylene films. Biosystems Engineering, 88(2), pp. 131-143, 2004. DOI: 10.1016/j.biosystemseng.2004.02.010.

[29] Gulmine, J.V., Janissek, P.R., Heise, H.M. \& Akcelrud, L., Degradation profile of polyethylene after artificial accelerated weathering. Polymer Degradation and Stability, 79(3), pp. 385-397, 2003. DOI: 10.1016/s0141-3910(02)00338-5.

[30] D'Amelia, R.P., Gentile S., Nirode W.F. \& Huang L., Quantitative analysis of copolymers and blends of polyvinyl acetate (PVAc) using Fourier transform infrared spectroscopy (FTIR) and elemental analysis (EA). World Journal of Chemical Education, 4(2), pp. 25-31.

[31] Matuana, L.M., Jin, S. \& Stark, N.M., Ultraviolet weathering of HDPE/wood-flour composites coextruded with a clear HDPE cap layer, 2011. Polymer Degradation and Stability, 96(1), pp. 97-106, 2011. DOI: 10.1016/j.polymdegradstab.2010.10.003.

[32] Babaghayou, M.I. et al., Photodegradation characterization and heterogeneity evaluation of the exposed and unexposed faces of stabilized and unstabilized LDPE films. Materials \& Design, 111(5), pp. 279-290, 2016.

DOI: 10.1016/j.matdes.2016.08.065.

[33] Kupper, L., Gulmine, J.V., Janissek, P.R. \& Heise, H.M., Attenuated total reflection infrared spectroscopy for micro-domain analysis of polyethylene samples after accelerated ageing within weathering chambers. Vibrational Spectroscopy, 34(1), pp. 63-72, 2004. DOI: 10.1016/j.vibspec.2003.05.002.

[34] Philip, M., Attwood, J., Hulme, A., Williams, G. \& Shipton, V., Evaluation of weathering in mixed polyethylene and polypropylene products. The Waste \& Resources Action Programme (WRAP) Report (UK), ISBN: 1-84405-092-0. 2004.

[35] Beg, M.D.H. \& Pickering, K.L., Accelerated weathering of unbleached and bleached Kraft wood fibre reinforced polypropylene composites. Polymer Degradation and Stability, 93(10), pp. 1939-1946, 2008.

DOI: $10.1016 /$ j.polymdegradstab.2008.06.012.

[36] Feldman, D., Polymer weathering: Photo-oxidation. Journal of Polymers and the Environment, 10(4), pp. 163-173, 2002. 